\title{
Early lactate clearance is associated with biomarkers of inflammation, coagulation, apoptosis, organ dysfunction and mortality in severe sepsis and septic shock
}

H Bryant Nguyen ${ }^{5,6^{*}}$, Manisha Loomba ${ }^{3}$, James J Yang ${ }^{4}$, Gordon Jacobsen ${ }^{4}$, Kant Shah ${ }^{1}$, Ronny M Otero ${ }^{1}$, Arturo Suarez ${ }^{1}$, Hemal Parekh ${ }^{6}$, Anja Jaehne ${ }^{1}$, Emanuel P Rivers ${ }^{1,2}$

\begin{abstract}
Background: Lactate clearance, a surrogate for the magnitude and duration of global tissue hypoxia, is used diagnostically, therapeutically and prognostically. This study examined the association of early lactate clearance with selected inflammatory, coagulation, apoptosis response biomarkers and organ dysfunction scores in severe sepsis and septic shock.

Methods: Measurements of serum arterial lactate, biomarkers (interleukin-1 receptor antagonist, interleukin-6, interleukin-8, interleukin-10, tumor necrosis factor-alpha, intercellular adhesion molecule-1, high mobility group box1, D-Dimer and caspase-3), and organ dysfunction scores (Acute Physiology and Chronic Health Evaluation II, Simplified Acute Physiology Score II, Multiple Organ Dysfunction Score, and Sequential Organ Failure Assessment) were obtained in conjunction with a prospective, randomized study examining early goal-directed therapy in severe sepsis and septic shock patients presenting to the emergency department (ED). Lactate clearance was defined as the percent change in lactate levels after six hours from a baseline measurement in the ED.

Results: Two-hundred and twenty patients, age $65.0+/-17.1$ years, were examined, with an overall lactate clearance of $35.5+/-43.1 \%$ and in-hospital mortality rate of $35.0 \%$. Patients were divided into four quartiles of lactate clearance, $-24.3+/-42.3,30.1+/-7.5,53.4+/-6.6$, and $75.1+/-7.1 \%$, respectively $(p<0.01)$. The mean levels of all biomarkers and organ dysfunction scores over 72 hours were significantly lower with higher lactate clearance quartiles $(p<0.01)$. There was a significant decreased in-hospital, 28-day, and 60-day mortality in the higher lactate clearance quartiles $(p<0.01)$.

Conclusions: Early lactate clearance as a surrogate for the resolution of global tissue hypoxia is significantly associated with decreased levels of biomarkers, improvement in organ dysfunction and outcome in severe sepsis and septic shock.
\end{abstract}

\section{Introduction}

The transition from sepsis to severe sepsis and septic shock is associated with a number of hemodynamic perturbations leading to global tissue hypoxia. Global tissue hypoxia accompanies a myriad of pathogenic mechanisms which contribute to the development of the multisystem organ dysfunction syndrome and increased

\footnotetext{
* Correspondence: hbryantn@yahoo.com
${ }^{5}$ Department of Emergency Medicine, Loma Linda University, Loma Linda,

* Correspondence: hbryantn@yahoo.com
${ }^{5}$ Department of Emergency Medicine, Loma Linda University, Loma Linda, CA
}

(c) 2010 Nguyen et al; licensee BioMed Central Ltd. This is an Open Access article distributed under the terms of the Creative Commons Attribution License (http://creativecommons.org/licenses/by/2.0), which permits unrestricted use, distribution, and reproduction in any medium, provided the original work is properly cited. between inflammation, coagulation and organ dysfunction; a clear cause and effect between global tissue hypoxia and these molecular processes leading to multiorgan failure in severe sepsis and septic shock remains unclear [3].

There is an increasing body of literature establishing the clinical utility of biomarkers as diagnostic, therapeutic and prognostic indicators in the management of patients presenting with severe sepsis and septic shock. 
These studies, largely derived from the intensive care unit (ICU) patient population comprise a mixed picture of pro-inflammatory, anti-inflammatory, coagulation and apoptosis biomarker responses $[4,5]$. However, the duration of stay for these patients prior to ICU admission whether on the general hospital ward or emergency department (ED) can be up to 24 hours [6]. Despite the abundance of knowledge in the ICU phase of severe sepsis and septic shock, little is known regarding the natural history of the biomarkers during the most proximal stage of disease presentation.

Studies targeting the early detection and eradication of global tissue hypoxia even after normalization of traditional vital signs (heart rate, blood pressure and urine output) have realized significant mortality benefit in severe sepsis and septic shock $[7,8]$. As a measure of tissue hypoxia and risk stratification, lactate measurements have now been incorporated into treatment protocols and care bundles [9]. We have previously reported that unresolved global tissue hypoxia reflected by inadequate lactate clearance during the early phase of resuscitation implicates organ dysfunction and increased mortality in severe sepsis and septic shock [10]. The mechanistic explanation for these observations remains un-elucidated. The purpose of this study is to examine the association of early lactate clearance with the biomarker activity of inflammation, coagulation, and apoptosis and the subsequent relationship to organ failure and outcome in early severe sepsis and septic shock.

\section{Materials and methods Study Design and Setting}

This study is an analysis of biological samples prospectively collected during and after a randomized, controlled study examining early goal-directed therapy for severe sepsis and septic shock. The study was performed at Henry Ford Hospital, Detroit, Michigan, and approved by the Institution Review Board for Human Research. The details of the original early goal-directed therapy study protocol have been previously published [7].

\section{Patient Selection}

Patients presenting to the ED of an urban academic tertiary care hospital from March 1997 to March 2001 were consented if they met enrollment criteria. Patients were included if they had 1) a source of infection suspected by the treating physician; 2) at least two of four systemic inflammatory response syndrome (SIRS) criteria [11]; and 3) either systolic blood pressure less than $90 \mathrm{~mm} \mathrm{Hg}$ after a $20-30 \mathrm{ml} / \mathrm{kg}$ crystalloid fluid bolus or lactate greater than or equal to $4 \mathrm{mmol} / \mathrm{L}$. Patients were excluded if they had age less than 18 years, pregnancy, acute cerebral vascular event, acute coronary syndrome, acute pulmonary edema, status asthmaticus, dysrhythmia as a primary diagnosis, contraindication to central venous catheterization, active gastrointestinal hemorrhage, seizure, drug overdose, burn injury, trauma, requirement for immediate surgery, uncured cancer, immunocompromised state, or do-not-resuscitate status. After meeting enrollment criteria, patients were invited to participate in the randomized protocol comparing early goal-directed therapy versus standard care and/or provide blood samples for serial biomarker measurements.

\section{Data Collection}

Patient demographics, hemodynamic variables, laboratories, sources of infection, comorbidities, and outcome were collected at baseline. Simultaneous measurements of serum arterial lactate, biomarkers and organ dysfunction scores were obtained at time $0,6,12,24,36,48,60$ and 72 hours after enrollment. Therapeutic interventions, such as antibiotics, fluids, packed red cells transfusion, vasoactive agents, and mechanical ventilation, given in the ED and up to 72 hours were recorded. Information required for the Acute Physiology and Chronic Health Evaluation (APACHE) II, Simplified Acute Physiology Score (SAPS) II, Multiple Organ Dysfunction Score (MODS), and Sequential Organ Failure Assessment (SOFA) score calculations were obtained at each time point. Patients were followed until in-hospital death or up to 60 days after enrollment.

\section{Biomarker Assays}

Biomarkers were chosen to represent pro-inflammatory, anti-inflammatory, coagulation, and apoptosis pathways involved in the pathogenesis of severe sepsis and septic shock. Analysis of the biomarkers for the purpose of this study was performed from September 2003 to December 2004. The pro-inflammatory biomarkers included interleukin-6 (IL-6), interleukin-8 (IL-8), tumor necrosis factor- $\alpha$ (TNF- $\alpha$ ), intercellular adhesion molecule-1 (ICAM-1), and high mobility group box-1 (HMGB-1). Anti-inflammatory biomarkers included interleukin-1 receptor antagonist (IL-1ra) and interleukin-10 (IL-10). Coagulation and apoptosis biomarkers included D-Dimer and caspase-8, respectively. Biomarker assays were performed by Biosite Inc, San Diego, California. Assays were performed using immunometric (sandwich) assays with NeutrAvidin-coated 384-well block microtiter plates (Pierce Biotechnology, Rockford, IL) and a Genesis RSP 200/8 Workstation (Tecan U.S., Durham, NC). Each sample was tested in duplicate. Before the assays, biotinylated primary antibody was diluted in assay buffer containing $10 \mathrm{mmol} / \mathrm{L}$ trishydroxymethylaminomethane $\mathrm{HCl}(\mathrm{pH} 8.0), 150 \mathrm{mmol} / \mathrm{L}$ sodium chloride, $1 \mathrm{mmol} / \mathrm{L}$ magnesium chloride, 0.1 
mmol/L zinc chloride, and $10 \mathrm{~mL} / \mathrm{L}$ polyvinyl alcohol $(9-10 \mathrm{kDa})$. The concentration of biotinylated antibody was predetermined by titration. The primary antibody (10 $\mu \mathrm{L}$ per well) was added to the plates and incubated. After washing, $10 \mathrm{~g} / \mathrm{L}$ bovine serum albumin and $1 \mathrm{~g} / \mathrm{L}$ sodium azide were added to the plate wells, which were then incubated at room temperature. Next, the plates were washed three times with borate-buffered saline containing $0.02 \%$ polyoxyethylene (20) sorbitan monolaurate (BBS-Tween).

For each sample, $10 \mu \mathrm{L}$ aliquots were added to each plate well and the plates were incubated. Following this incubation, the plates were washed three times and alkaline phosphatase-conjugated antibody $(10 \mu \mathrm{L}$ per well $)$ was added to each plate well and further incubated. The concentration of the alkaline phosphatase-conjugated antibody was predetermined to ensure a linear profile in the dynamic range of interest. After additional incubation, the plates were washed nine times with BBS-Tween. AttoPhos substrate (S1011, Promega, Madison, WI), a fluorescence-enhancing substrate previously diluted in AttoPhos buffer (S1021, Promega), was then added to aid in the measurement of the activity of antibody-conjugated alkaline phosphatase bound in each well. The plates were then scanned in a fluorometer (Tecan Spectrafluor, Tecan U.S.) using an excitation wavelength of $430 \mathrm{~nm}$ and an emission wavelength of $570 \mathrm{~nm}$. Each well was scanned 6 times at 114-sec intervals, and the rate of fluorescence generation was calculated. Calibration curves were derived from eight points tested at multiple locations on the assay plate using a 4-parameter logistic fit, from which sample concentrations were subsequently calculated. Each plate included calibration wells consisting of multiple analyte concentrations and control samples. Calibration curves for each biomarker assay were generated for IL-1ra $(150-30,000 \mathrm{pg} / \mathrm{mL})$, IL-6 (20-10,000 pg/mL), IL-8 (15-3,000 pg/mL), IL-10 (15$1,000 \mathrm{pg} / \mathrm{mL})$, TNF- $\alpha(20-2,000 \mathrm{pg} / \mathrm{mL})$, ICAM-1 (2.5$900 \mathrm{ng} / \mathrm{mL})$, HMGB-1 (0.5-100 ng./mL), D-Dimer (0.5$40 \mu \mathrm{g} / \mathrm{mL})$, and caspase-3 (0.1-200 $\mathrm{ng} / \mathrm{mL})$.

\section{Patient Stratification}

Lactate clearance was defined as the percent change in lactate level after six hours from a baseline measurement. It is calculated by using the following formula: lactate at ED presentation (hour 0) minus lactate at hour 6, divided by lactate at ED presentation, then multiplied by 100. A positive value denotes a decrease or clearance of lactate, whereas a negative value denotes an increase in lactate after 6 hours of intervention.

$$
\text { Lactate clearance }=\frac{\left(\text { Lactate }^{\text {ED Presentation }}-\text { Lactate }{ }^{\text {Hour } 6}\right) \times 100}{\text { Lactate }^{\text {ED Presentation }}}
$$

The study population was sorted by increasing lactate clearance and divided into four groups with equivalent number of patients for comparisons among lactate clearance quartiles.

\section{Statistical Analysis}

For the purpose of this study, lactate clearance, biomarkers and organ dysfunction scores were analyzed in all patients enrolled in the study, irrespective of the treatment group assigned to the patients. We a priori accepted that lactate clearance is a reflection of the therapies received by the patients, such as fluids, red cells transfusion, vasopressors, and inotrope; rather than a function of the randomization assignment to early goal-directed therapy or standard care. Descriptive statistics were used to summarize patient characteristics. The Kruskal-Wallis test was used to compare numeric variables (e.g., vital signs, hemodynamic variables, laboratories, biomarker measurements, and organ dysfunction scores over 72 hours) among patients stratified by lactate clearance quartiles. The standard Chi-square test was used to compare categorical variables (e.g., septic shock, culture status, and therapeutic interventions) among the lactate clearance quartiles. Mortality outcomes were compared among the lactate clearance quartiles using Chi-square analysis, with Kaplan-Meier estimation used to obtain mortality rates up to 12 months. A two-tailed $p$-value less than 0.05 was considered statistically significant. Data are presented as percentage or mean \pm standard deviation.

\section{Results}

Two hundred and twenty-two patients, age $65.0 \pm 17.1$ years, were enrolled within $1.6 \pm 2.1$ hours of ED presentation. The initial hemodynamic parameters included central venous pressure of $5.1 \pm 8.5 \mathrm{~mm} \mathrm{Hg}$, mean arterial pressure $74.8 \pm 25.7 \mathrm{~mm} \mathrm{Hg}$, central venous oxygen saturation $49.2 \pm 12.6$ percent, and lactate $7.4 \pm$ $4.6 \mathrm{mmol} / \mathrm{L}$. Fifty-five percent of patients had septic shock, 37.1\% had blood culture positive, and the most common source of infection was pneumonia. Lactate clearance was $35.5 \pm 43.1$ percent and in-hospital mortality rate $35.0 \%$ (Table 1 ).

The lactate clearance quartiles were $-24.3 \pm 42.3,30.1$ $\pm 7.5,53.4 \pm 6.6$, and $75.1 \pm 7.1 \%$, respectively $(p<$ 0.01 , Table 2). There was no significant difference among the lactate clearance quartiles with respect to age, demographics, co-morbidities, blood culture positive, hemodynamic variables, baseline lactate, and other laboratories (except platelets, total bilirubin and albu$\mathrm{min}$ ). There was significant difference in the number of septic shock patients among the lactate clearance quartiles, with the highest percent of septic shock patients in the lowest clearance quartile $(p<0.01)$. Quartiles 
Table 1 Patient characteristics.

\begin{tabular}{|c|c|}
\hline No. Patients & 220 \\
\hline Age (years) & $65.0 \pm 17.1$ \\
\hline Male:Female (\%) & 54.1:45.9 \\
\hline Time from ED arrival to enrollment (hours) & $1.6 \pm 2.1$ \\
\hline Length of hospital stay (days) & $13.9 \pm 16.6$ \\
\hline \multicolumn{2}{|l|}{ Vital signs and hemodynamic variables } \\
\hline Temperature $\left({ }^{\circ} \mathrm{C}\right)$ & $36.3 \pm 2.8$ \\
\hline Heart rate (beats per $\min$ ) & $117.1 \pm 30.1$ \\
\hline Systolic blood pressure $(\mathrm{mm} \mathrm{Hg})$ & $107.5 \pm 36.2$ \\
\hline Mean arterial pressure $(\mathrm{mm} \mathrm{Hg})$ & $74.8 \pm 25.7$ \\
\hline Shock index (heart rate/systolic blood pressure) & $1.2 \pm 0.5$ \\
\hline Respiratory rate (breaths per min) & $31.5 \pm 11.1$ \\
\hline CVP $(\mathrm{mm} \mathrm{Hg})$ & $5.1 \pm 8.5$ \\
\hline $\mathrm{ScvO}_{2}(\%)$ & $49.2 \pm 12.6$ \\
\hline \multicolumn{2}{|l|}{ Laboratories } \\
\hline White blood cells $\left(\times 10^{3}\right.$ per $\left.\mathrm{mm}^{3}\right)$ & $14.0 \pm 9.0$ \\
\hline Hemoglobin $(\mathrm{g} / \mathrm{dL})$ & $11.4 \pm 2.7$ \\
\hline Platelets $\left(\times 10^{3}\right.$ per $\left.\mu \mathrm{L}\right)$ & $211.5 \pm 122.0$ \\
\hline Creatinine $(\mathrm{mg} / \mathrm{dL})$ & $2.9 \pm 2.0$ \\
\hline Glucose $(\mathrm{mg} / \mathrm{dL})$ & $259.4 \pm 327.8$ \\
\hline Anion gap (mEq/L) & $21.5 \pm 8.0$ \\
\hline Total bilirubin (mg/dL) & $1.5 \pm 2.1$ \\
\hline Albumin $(\mathrm{g} / \mathrm{dL})$ & $2.8 \pm 0.7$ \\
\hline Lactate $(\mathrm{mmol} / \mathrm{L})$ & $7.4 \pm 4.6$ \\
\hline Lactate clearance (\%) & $35.5 \pm 43.1$ \\
\hline Septic shock (\%) & 55.0 \\
\hline Culture positive (\%) & 65.6 \\
\hline Blood culture positive (\%) & 37.1 \\
\hline \multicolumn{2}{|l|}{ Organ dysfunction scores } \\
\hline APACHE ॥ & $21.5 \pm 7.0$ \\
\hline SAPS ॥ & $49.8 \pm 11.0$ \\
\hline MODS & $7.6 \pm 3.1$ \\
\hline SOFA & $6.5 \pm 2.9$ \\
\hline \multicolumn{2}{|l|}{ Source of infection (\%) } \\
\hline Pneumonia & 39.5 \\
\hline Urinary tract infection & 13.2 \\
\hline Intra-abdominal & 4.1 \\
\hline Other & 43.2 \\
\hline \multicolumn{2}{|l|}{ Comorbidities (\%) } \\
\hline Chronic obstructive pulmonary disease & 16.4 \\
\hline Chronic renal insufficiency & 20.9 \\
\hline Congestive heart failure & 30.9 \\
\hline Coronary artery disease & 22.7 \\
\hline Diabetes mellitus & 30.5 \\
\hline Hypertension & 67.3 \\
\hline Liver disease & 21.4 \\
\hline \multicolumn{2}{|l|}{ Outcome (\%) } \\
\hline In-hospital mortality & 35.0 \\
\hline
\end{tabular}

28-day mortality 36.4

60-day mortality $\quad 42.7$

Vital signs, hemodynamic variables, laboratories and organ dysfunction scores represent baseline values at patient enrollment. ED - emergency department; CVP - central venous pressure; $\mathrm{ScvO}_{2}$ - central venous oxygen saturation; Acute Physiology and Chronic Health Evaluation (APACHE) II; Simplified Acute Physiology Score (SAPS) II; Multiple Organ Dysfunction Score (MODS);

Sequential Organ Failure Assessment (SOFA).

with lower lactate clearance required significantly more vasopressor and mechanical ventilation during the first 6 hours. After 6 hours, only vasopressor remained significantly higher in lower lactate clearance quartiles (Table 3).

The mean levels of all biomarkers averaged over 72 hours were significantly lower with higher lactate clearance quartiles (Table 4, Figure 1). Similarly, the mean organ dysfunction scores averaged over 72 hours were significantly lower with higher lactate clearance quartiles (Table 4, Figure 2).

There was significant decreased in-hospital, 28-day and 60-day mortality for higher lactate clearance quartiles (Table 4). Kaplan-Meier survival analysis showed a survival benefit over 12 months for patients in the higher lactate clearance quartiles (Figure 3).

\section{Discussion}

The current pathogenesis of severe sepsis and septic shock is described as a complex interaction of pro- and anti-inflammation, coagulation, and apoptosis triggered by the infecting microorganism. The bacteria outer membrane lipopolysaccharide molecule (LPS, endotoxin) activates a toll-like receptor 4 (TLR-4) signaling pathway that results in translocation of nuclear factor- $\kappa \mathrm{B}$ (NF$\kappa \mathrm{B})$ and production of inflammatory cytokines. The result is a production of pro-inflammatory cytokines that are balanced by an array of anti-inflammatory cytokines. The coagulation pathway is also activated by LPSmediated signaling and further regulated by the cytokines, inducing the production of tissue factor, prothrombin conversion to thrombin, and fibrin production. Fibrinolysis is impaired due to increased production of plasminogen-activator inhibitor type-1 (PAI-1), decreased generation of plasmin and reduced removal of fibrin. The procoagulant state further down regulates the anticoagulant proteins, antithrombin, protein $\mathrm{C}$, and tissue factor pathway inhibitor. The net result is deposition of fibrin clots throughout the endothelium, resulting in inadequate blood flow, organ hypoperfusion, global tissue hypoxia and cell death $[3,12]$.

Clinically, lactate has been studied as a measure of illness severity in circulatory shock for several decades dating back to the 1800 's $[13,14]$. Although there are 
Table 2 Patient characteristics, basline vital signs, hemodynamics and laboratories by lactate clearance quartile.

\begin{tabular}{|c|c|c|c|c|c|}
\hline & $\begin{array}{c}\text { Quartile } 1 \\
\mathrm{~N}=55\end{array}$ & $\begin{array}{c}\text { Quartile } 2 \\
\mathrm{~N}=55\end{array}$ & $\begin{array}{c}\text { Quartile } 3 \\
\mathrm{~N}=55\end{array}$ & $\begin{array}{c}\text { Quartile } 4 \\
\mathrm{~N}=55\end{array}$ & P-value \\
\hline Lactate clearance (\%) & $-24.3 \pm 42.3$ & $30.1 \pm 7.5$ & $53.4 \pm 6.6$ & $75.1 \pm 7.1$ & $<0.01$ \\
\hline Age (years) & $63.2 \pm 16.5$ & $68.2 \pm 17.5$ & $65.7 \pm 15.7$ & $66.7 \pm 18.4$ & 0.29 \\
\hline Septic shock (\%) & 70.9 & 58.2 & 54.6 & 36.4 & $<0.01$ \\
\hline Culture positive (\%) & 45.5 & 33.3 & 42.6 & 32.7 & 0.41 \\
\hline Blood culture positive (\%) & 43.4 & 34.0 & 42.3 & 28.9 & 0.36 \\
\hline \multicolumn{6}{|l|}{ Vital signs and hemodynamics } \\
\hline Temperature $\left({ }^{\circ} \mathrm{C}\right)$ & $36.3 \pm 3.0$ & $36.5 \pm 3.2$ & $36.1 \pm 2.7$ & $36.4 \pm 2.5$ & 0.67 \\
\hline Heart rate (beats per min) & $113.8 \pm 25.4$ & $117.0 \pm 27.6$ & $120.0 \pm 30.9$ & $117.8 \pm 36.0$ & 0.70 \\
\hline Systolic blood pressure $(\mathrm{mm} \mathrm{Hg})$ & $108.0 \pm 39.7$ & $103.3 \pm 30.2$ & $108.1 \pm 35.0$ & $110.4 \pm 40.0$ & 0.88 \\
\hline Mean arterial pressure $(\mathrm{mm} \mathrm{Hg})$ & $76.1 \pm 26.6$ & $71.2 \pm 21.8$ & $75.8 \pm 26.9$ & $76.1 \pm 27.4$ & 0.81 \\
\hline Shock index (HR/SBP) & $1.2 \pm 0.5$ & $1.2 \pm 0.4$ & $1.2 \pm 0.5$ & $1.2 \pm 0.6$ & 0.76 \\
\hline Respiratory rate (breaths per min) & $29.5 \pm 10.3$ & $30.4 \pm 10.9$ & $34.2 \pm 11.8$ & $32.2 \pm 10.9$ & 0.16 \\
\hline CVP $(\mathrm{mm} \mathrm{Hg})$ & $6.0 \pm 8.7$ & $4.5 \pm 8.7$ & $3.9 \pm 8.9$ & $5.7 \pm 8.2$ & 0.16 \\
\hline $\mathrm{ScvO}_{2}(\%)$ & $49.3 \pm 12.9$ & $51.4 \pm 12.0$ & $44.1 \pm 12.6$ & $51.2 \pm 12.3$ & 0.28 \\
\hline \multicolumn{6}{|l|}{ Laboratories } \\
\hline White blood cells $\left(\times 10^{3}\right.$ per $\left.\mathrm{mm}^{3}\right)$ & $11.8 \pm 7.1$ & $13.5 \pm 8.9$ & $15.0 \pm 10.5$ & $15.6 \pm 9.1$ & 0.13 \\
\hline Hemoglobin $(\mathrm{g} / \mathrm{dL})$ & $11.6 \pm 2.6$ & $11.0 \pm 2.9$ & $11.5 \pm 2.5$ & $11.3 \pm 2.7$ & 0.68 \\
\hline Platelets $\left(\times 10^{3}\right.$ per $\left.\mu \mathrm{L}\right)$ & $163.7 \pm 82.2$ & $184.0 \pm 116.7$ & $254.1 \pm 135.6$ & $244.4 \pm 124.8$ & $<0.01$ \\
\hline Creatinine $(\mathrm{mg} / \mathrm{dL})$ & $2.5 \pm 2.2$ & $2.5 \pm 1.7$ & $2.6 \pm 1.9$ & $2.7 \pm 2.4$ & 0.94 \\
\hline Glucose (mg/dL) & $303.5 \pm 421.4$ & $172.1 \pm 150.6$ & $240.9 \pm 275.0$ & $321.1 \pm 382.0$ & 0.07 \\
\hline Anion gap (mEq/L) & $22.2 \pm 9.6$ & $20.0 \pm 7.3$ & $21.5 \pm 7.9$ & $22.2 \pm 6.9$ & 0.52 \\
\hline Total bilirubin (mg/dL) & $1.9 \pm 2.3$ & $1.9 \pm 3.1$ & $1.2 \pm 1.4$ & $0.9 \pm 0.7$ & 0.03 \\
\hline Albumin $(\mathrm{g} / \mathrm{dL})$ & $2.7 \pm 0.7$ & $2.8 \pm 0.7$ & $2.8 \pm 0.7$ & $3.1 \pm 0.6$ & $<0.01$ \\
\hline Lactate $(\mathrm{mmol} / \mathrm{L})$ & $7.5 \pm 5.8$ & $7.3 \pm 4.9$ & $7.3 \pm 3.8$ & $7.3 \pm 3.5$ & 0.47 \\
\hline
\end{tabular}

Lactate clearance - defined as the percent change in lactate level after six hours from baseline measurement $=\left[\left(\right.\right.$ Lactate ${ }^{\mathrm{ED}}$ Presentation - Lactate $\left.^{\text {Hour }}{ }^{6}\right) /$ Lactate ${ }^{\mathrm{ED}}$ Presentation $] \times 100$. A positive value denotes a decrease or clearance of lactate, whereas a negative value denotes an increase in lactate after 6 hours of intervention. Lactate clearance quartile - derived from sorting the study population by increasing lactate clearance and separating into four groups with equivalent number of patients. $\mathrm{HR}$ - heart rate; SBP - systolic blood pressure; CVP - central venous pressure; $\mathrm{ScvO}_{2}-\mathrm{Central}$ venous oxygen saturation.

Table 3 Therapies during the first 6 hours in the ED and from 7 to 72 hours in the ICU by lactate clearance quartile.

\begin{tabular}{|c|c|c|c|c|c|}
\hline & $\begin{array}{c}\text { Quartile } 1 \\
\mathrm{~N}=55\end{array}$ & $\begin{array}{c}\text { Quartile } 2 \\
\mathrm{~N}=55\end{array}$ & $\begin{array}{c}\text { Quartile } 3 \\
\mathrm{~N}=55\end{array}$ & $\begin{array}{c}\text { Quartile } 4 \\
\mathrm{~N}=55\end{array}$ & P-value \\
\hline \multicolumn{6}{|l|}{ Therapies in first 6 hours } \\
\hline Antibiotics (\%) & 72.2 & 77.5 & 72.1 & 75.0 & 0.95 \\
\hline Appropriate Antibiotics (\%) & 86.3 & 77.5 & 90.7 & 88.9 & 0.59 \\
\hline Fluids (mL) & $4531.2 \pm 2745.3$ & $4263.5 \pm 2872.9$ & $4266.8 \pm 3449.5$ & $3741.7 \pm 3136.4$ & 0.27 \\
\hline Transfusion (\%) & 54.6 & 41.8 & 26.4 & 43.6 & 0.27 \\
\hline Vasopressor (\%) & 50.9 & 36.4 & 27.3 & 14.6 & $<0.01$ \\
\hline Inotrope/dobutamine (\%) & 5.5 & 3.6 & 9.1 & 12.7 & 0.29 \\
\hline Mechanical ventilation (\%) & 74.6 & 50.9 & 58.2 & 38.2 & $<0.01$ \\
\hline \multicolumn{6}{|l|}{ Therapies from 7 to 72 hours } \\
\hline Antibiotics (\%) & 95.0 & 93.9 & 100 & 97.0 & 0.50 \\
\hline Fluids $(\mathrm{mL})$ & $8817.2 \pm 5818.1$ & $9666.7 \pm 6555.2$ & $10329.8 \pm 6866.6$ & $7141.9 \pm 4097.8$ & 0.06 \\
\hline Transfusion (\%) & 23.6 & 20.0 & 20.0 & 27.3 & 0.77 \\
\hline Vasopressor (\%) & 47.3 & 47.3 & 30.9 & 18.2 & $<0.01$ \\
\hline Inotrope/dobutamine (\%) & 10.9 & 14.6 & 9.1 & 12.7 & 0.83 \\
\hline Mechanical ventilation (\%) & 12.7 & 14.6 & 7.3 & 7.3 & 0.48 \\
\hline
\end{tabular}

Lactate clearance quartile - derived from sorting the study population by increasing lactate clearance and separating into four groups with equivalent number of patients. 
Table 4 Biomarker levels and organ dysfunction scores averaged over 72 hours by lactate clearance quartile.

\begin{tabular}{|c|c|c|c|c|c|}
\hline & $\begin{array}{c}\text { Quartile } 1 \\
\mathrm{~N}=55\end{array}$ & $\begin{array}{c}\text { Quartile } 2 \\
\mathrm{~N}=55\end{array}$ & $\begin{array}{c}\text { Quartile } 3 \\
\mathrm{~N}=55\end{array}$ & $\begin{array}{c}\text { Quartile } 4 \\
\mathrm{~N}=55\end{array}$ & P-value \\
\hline \multicolumn{6}{|c|}{ Biomarkers over 72 hours } \\
\hline IL-1ra (ng/mL) & $8455.9 \pm 8838.4$ & $7565.4 \pm 8289.1$ & $6421.3 \pm 7957.5$ & $2792.6 \pm 3635.7$ & $<0.01$ \\
\hline IL-6 (pg/mL) & $2839.5 \pm 3487.0$ & $2680.1 \pm 3174.0$ & $2426.7 \pm 3269.4$ & $663.2 \pm 1583.5$ & $<0.01$ \\
\hline IL-8 (pg/mL) & $480.3 \pm 802.4$ & $355.3 \pm 559.1$ & $356.3 \pm 735.1$ & $76.4 \pm 218.0$ & $<0.01$ \\
\hline IL-10 (pg/mL) & $303.6 \pm 298.7$ & $227.4 \pm 218.5$ & $180.2 \pm 243.4$ & $85.4 \pm 121.9$ & $<0.01$ \\
\hline TNF- $\alpha(\mathrm{pg} / \mathrm{mL})$ & $65.2 \pm 105.9$ & $50.9 \pm 69.2$ & $47.4 \pm 72.8$ & $19.6 \pm 19.8$ & $<0.01$ \\
\hline ICAM-1 (ng/mL) & $409.1 \pm 208.1$ & $413.3 \pm 204.5$ & $379.7 \pm 213.8$ & $299.2 \pm 156.1$ & $<0.01$ \\
\hline HMGB-1 (ng/mL) & $4.6 \pm 8.3$ & $5.0 \pm 10.4$ & $2.5 \pm 3.3$ & $1.6 \pm 2.4$ & $<0.01$ \\
\hline D-Dimer $(\mu / \mathrm{mL})$ & $20.8 \pm 9.5$ & $18.9 \pm 9.5$ & $18.1 \pm 8.9$ & $15.7 \pm 9.7$ & 0.04 \\
\hline Caspase-3 (ng/mL) & $3.8 \pm 7.5$ & $2.4 \pm 3.8$ & $1.9 \pm 2.6$ & $1.1 \pm 0.8$ & $<0.01$ \\
\hline \multicolumn{6}{|c|}{ Organ dysfunction over 72 hours } \\
\hline APACHE II & $16.8 \pm 6.3$ & $16.6 \pm 6.4$ & $14.8 \pm 6.9$ & $11.6 \pm 6.0$ & $<0.01$ \\
\hline SAPS $\|$ & $43.9 \pm 12.4$ & $44.6 \pm 43.5$ & $39.5 \pm 12.0$ & $34.2 \pm 11.9$ & $<0.01$ \\
\hline MODS & $8.0 \pm 3.5$ & $7.0 \pm 4.0$ & $5.7 \pm 4.2$ & $3.4 \pm 2.5$ & $<0.01$ \\
\hline SOFA & $8.8 \pm 3.3$ & $8.0 \pm 3.4$ & $6.8 \pm 4.3$ & $4.4 \pm 2.7$ & $<0.01$ \\
\hline \multicolumn{6}{|l|}{ Outcome (\%) } \\
\hline In-hospital mortality & 52.7 & 41.8 & 29.1 & 16.4 & $<0.01$ \\
\hline 28-day mortality & 54.9 & 49.0 & 33.5 & 21.6 & $<0.01$ \\
\hline 60-day mortality & 63.1 & 52.9 & 38.0 & 33.6 & 0.01 \\
\hline
\end{tabular}

Lactate clearance quartile - derived from sorting the study population by increasing lactate clearance and separating into four groups with equivalent number of patients. IL-1 ra - interleukin-1 receptor antagonist; IL-6 - interleukin-6; IL-8 - interleukin-8; IL-10 - interleukin-10; TNF- $\alpha$ - tumor necrosis factor- $\alpha$; ICAM-1 -

intercellular adhesion molecule-1; HMGB-1 - high mobility group box-1; Acute Physiology and Chronic Health Evaluation (APACHE) II; Simplified Acute Physiology Score (SAPS) II; Multiple Organ Dysfunction Score (MODS); Sequential Organ Failure Assessment (SOFA).

various explanations regarding the mechanisms responsible for lactate accumulation in severe sepsis and septic shock, it remains a robust surrogate marker for the development of multi-organ failure and poor outcome [15-19]. Similar observations have been noted in other conditions of critical illness, including pediatric and adult cardiac surgery [20-22], the post-resuscitation period of cardiac arrest [23,24], trauma [25], general surgical [26], and liver surgery patients [27]. A recurring theme in these studies is the inflammatory response plays a crucial mechanistic intermediate between lactate clearance and the development of multi-organ failure.

Evidence-based guidelines have recommended that an elevated lactate is sufficient to diagnosis shock, irrespective of hypotension [28]. Sepsis with lactate level greater than or equal to $4 \mathrm{mmol} / \mathrm{L}$ is associated with high mortality and is an indication to initiate treatment protocols and care bundles $[7,9,29]$. We previously reported a significant inverse relationship between lactate clearance (or resolution of global tissue hypoxia) during the first 6 hours and mortality in severe sepsis and septic shock [10]. We have also shown that early goal-directed therapy targeting global tissue hypoxia to be more effective than standard care in decreasing lactate during the first six hours of intervention [7]. In this study, we found a significant association between improving lactate clearance in the first 6 hours and a corresponding decrease in mean biomarker levels over 72 hours. This potential mechanistic link was also positively associated with improved organ dysfunction scores and decreased mortality.

The association between poor lactate clearance and the need for vasopressor therapy is consistent with observations that pathogenic but reversible correlates of outcome may be established in the first few hours of disease presentation. A limited course of vasopressor therapy indicates reversible tissue hypoxia; however, prolonged vasopressor usage for hemodynamic support is associated with worse lactate clearance and thus outcome [30]. Additionally, lactate clearance has been shown to be significantly associated with improved microcirculatory flow [31]. This provides supportive evidence for the mechanistic connection between prolonged vasopressor use, tissue ischemia, persistent lactate elevation, morbidity and mortality. Our results further support the notion that tissue hypoxia plays a crucial role in the early complex mechanisms leading to the endothelial response in severe sepsis and septic shock, rather than a terminal or irreversible event following inflammation and coagulopathy [1]. Thus a goaldirected hemodynamic optimization strategy targeting the resolution of global tissue hypoxia, reflected by 


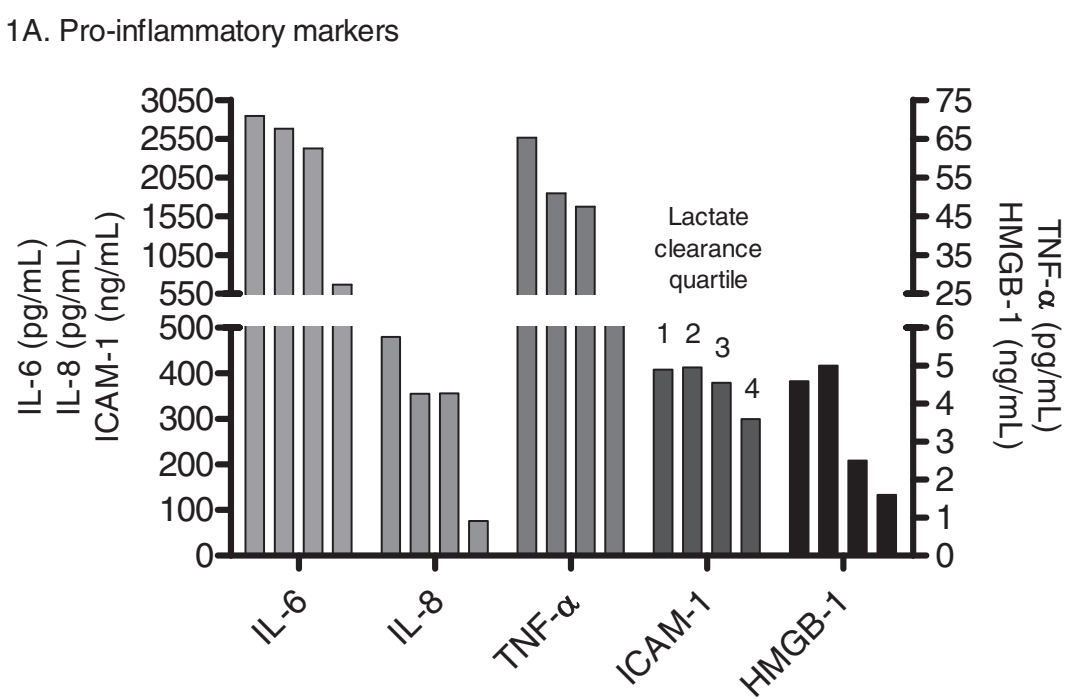

1B. Anti-inflammatory, coagulation, and apoptosis markers

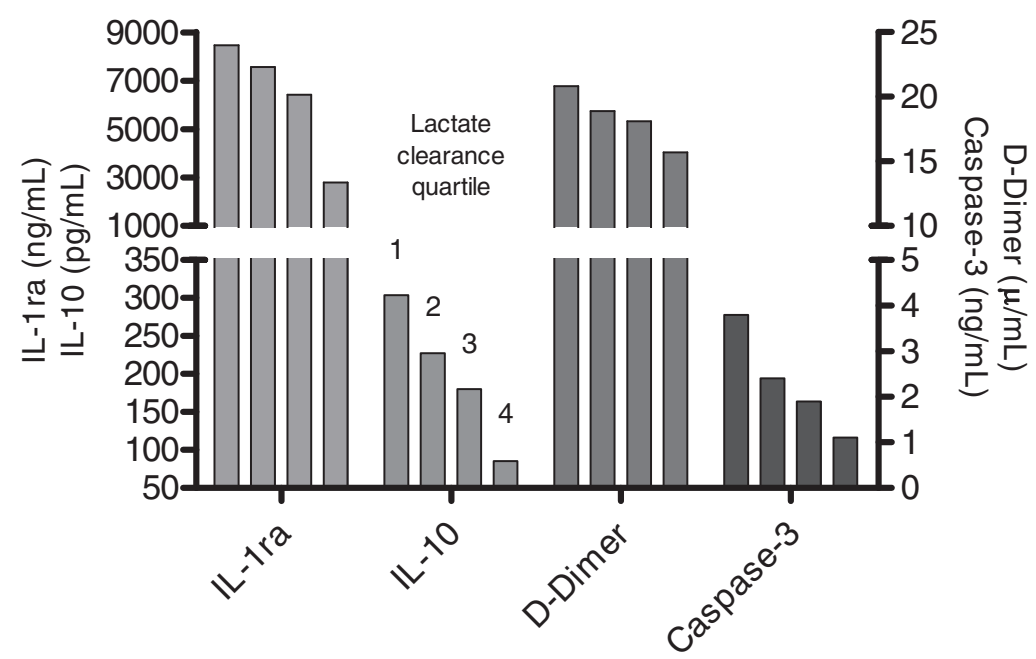

Figure 1 Mean biomarker levels averaged over $\mathbf{7 2}$ hours based on lactate clearance quartile. The mean levels of pro-inflammatory markers interleukin-6 (IL-6), interleukin-8 (IL-8), tumor necrosis factor- $\alpha$ (TNF- $\alpha$ ), intercellular adhesion molecule-1 (ICAM-1), and high mobility group box-1 (HMGB-1); anti-inflammatory markers interleukin-1 receptor antagonist (IL-1ra) and interleukin-10 (IL-10); coagulation marker D-Dimer; and apoptosis marker Caspase-3 are significantly lower over 72 hours with higher lactate clearance quartiles.

clearance of lactate, will likely reverse the diffuse endothelial and microcirculatory dysfunction in patients who most likely will benefit [2].

In-vitro models have shown that hypoxia induces the pro-inflammatory cytokines, IL-1, IL-6, IL-8, and TNF$\alpha$ [32-36]. These cytokines then increase the expression of intercellular adhesion molecules (ICAM-1) and further activation and migration of neutrophils [37-39]. In humans, IL-6 and IL-8 elevations correlated significantly to lactate levels (as a measure of tissue hypoxia) in sepsis $[40,41]$. Recently, combined serial lactate and cytokine levels (IL-1, IL-6, IL-10, and HMGB-1) in septic shock patients were shown to be useful indicators of clinical outcome $[42,43]$. In our study, IL-1ra, IL-6, IL-8, IL-10, and TNF- $\alpha$ were measured due to their close association with the early pro- and antiinflammatory response. HMGB-1 was chosen as a proinflammatory mediator that appears much later than the other cytokines after LPS stimulation [44]. We have shown that the higher lactate clearance in the 


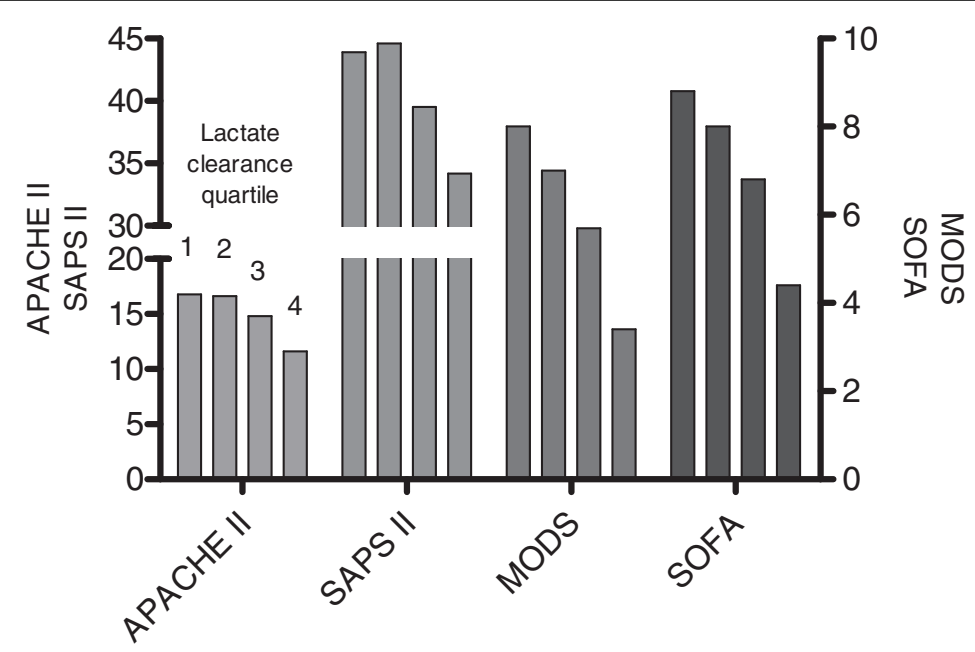

Figure 2 Mean organ dysfunction scores averaged over $\mathbf{7 2}$ hours based on lactate clearance quartile. The Acute Physiology and Chronic Health Evaluation (APACHE) II, Simplified Acute Physiology Score (SAPS) II, Multiple Organ Dysfunction Score (MODS), and Sequential Organ Failure Assessment (SOFA) score are significantly lower over 72 hours with higher lactate clearance quartiles.

first 6 hours, the greater the decrease in all pro-inflammatory and anti-inflammatory cytokines measured over 72 hours.

Hematologic abnormalities (leukocytotosis, anemia and thrombocytopenia) are common in severe sepsis and septic shock. Alterations in the levels of various mediators of coagulation and fibrinolysis have been reported to be associated with disseminated intravascular coagulation (DIC) and mortality [45]. Patients with SIRS and sepsis having DIC were shown to have higher serial lactate levels over 4 days compared to those patients without DIC, suggesting a pathogenic link between tissue hypoxia and intravascular coagulation [46]. While no single marker measured at hospital admission is sufficiently sensitive or specific in diagnosing DIC, we chose to measure D-Dimer as a marker of coagulation in this study as it is widely available, a correlate to the pro-inflammatory cytokine levels, and a valuable screening marker for organ failure and mortality [47-49]. It also has been used previously as an

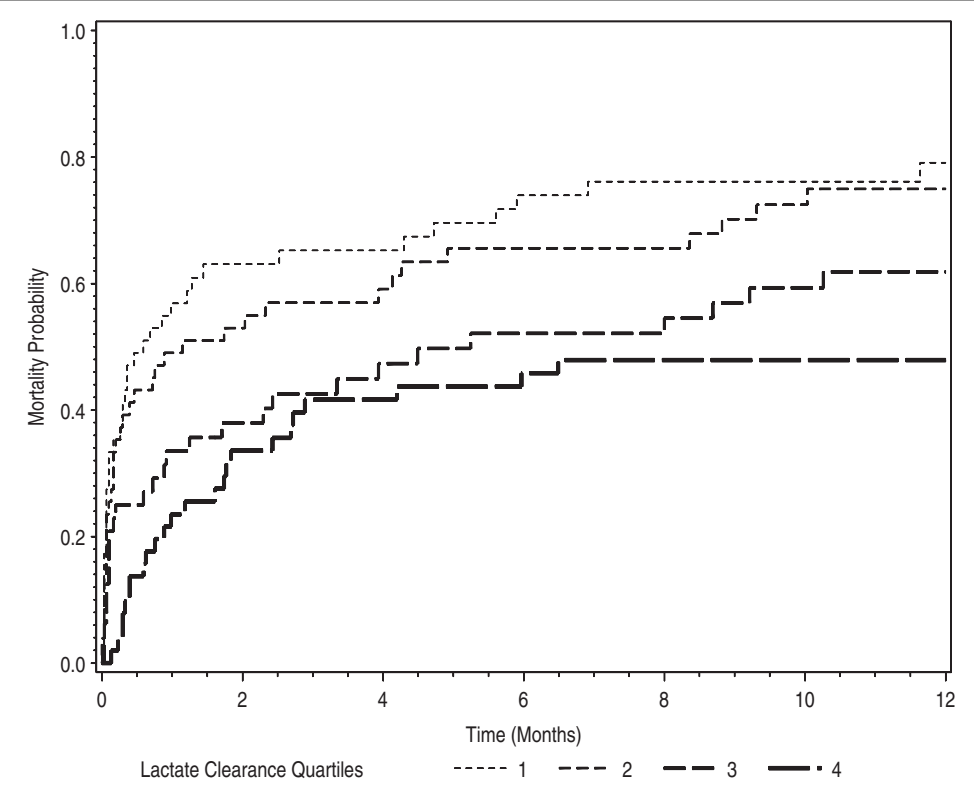

Figure 3 Kaplan-Meier 12-month survival analysis based on lactate clearance quartile. Lactate clearance quartile 1, 2, 3, and 4 have lactate clearance of $-24.3 \pm 42.3,30.1 \pm 7.5,53.4 \pm 6.6$, and $75.1 \pm 7.1 \%$, respectively, during the first 6 hours in the emergency department $(p<0.01)$. 
indicator of response to therapies such as recombinant human activated protein $C$ in severe sepsis [50]. In our study, we showed that improvements in coagulation (reflected by a decrease in D-Dimer levels over 72 hours) corresponded with lactate clearance during the first 6 hours. Our results provide further evidence that tissue hypoxia may be a preceding or parallel event to the pro-coagulant state in severe sepsis and septic shock, and therapies targeting tissue hypoxia may play a crucial role in reversing this coagulopathy.

Cell death through apoptosis is a highly regulated process in the presence or absence of inflammation [51]. Apoptosis is initiated by two pathways: 1) a receptor activated, caspase- 8 mediated (extrinsic) pathway; and 2) a mitochondrial initiated caspase- 9 mediated (intrinsic) pathway. Either of these caspases can activate caspase-3 in the common pathway resulting in final cell death. Caspases are pro-apoptotic proenzymes that inactivate protective proteins and contribute to cell death by direct cellular disassembly via cell shrinkage (pyknosis) and nuclear fragmentation (karyorrhexis) [52]. The regulation of apoptosis in sepsis is complex, as the infecting pathogen may inhibit or induce apoptosis, involving both the extrinsic and intrinsic pathways, to enhance its damaging effects to the host [53]. Caspase activation in apoptosis is an energy-dependent process. Hypoxia can induce apoptosis as long as cells have an adequate amount of adenosine triphosphate. Previously, apoptosis was believed to occur via the intrinsic pathway with cytochrome c release and caspase-9 activation in oxygen-deprived cells [54]. However, the extrinsic pathway may also play an important role in oxidative stress induced apoptosis [53]. In this study, caspase-3 as a marker of the final common pathway in apoptosis was shown to be elevated over 72 hours in patients with decreased lactate clearance, compared to lower caspase3 in patients with higher lactate clearance. This finding supports the premise that tissue hypoxia in severe sepsis and septic shock is associated with increased apoptosis, suggesting that the ill effects resulting in cell death may be mitigated by resolution of global tissue hypoxia.

Our results provide evidence that the design and interpretation of future clinical trials should consider the early stages of severe sepsis and septic shock. Previously, two studies failed to show significant outcome benefit with inhibition of TNF- $\alpha$ and IL-1ra in severe sepsis and septic shock patients enrolled in the ICU $[55,56]$. The association of lactate clearance with these targeted biomarkers shown in our study suggests that the severity of tissue hypoxia should be part of patient selection criteria in studies examining novel therapies that may alter its down stream effects. The failure to consider the magnitude, duration of tissue hypoxia and the timing of patient enrollment in clinical trials will likely result in some degree of hemodynamic heterogeneity confounding any treatment effect [57].

The results of our study do not confirm a causal relationship, but an association between lactate clearance in the first 6 hours and biomarker response over 72 hours. High lactate clearance quartiles had fewer patients in septic shock obviously requiring less vasopressor usage, but no difference in antibiotic and fluid administration. Lactate clearance over 6 hours may also depend on the patient's underlying comorbidities, such as liver disease, and the disease process rather than solely on the therapies themselves. However, baseline demographics, comorbidities, lactate and hemodynamic variables were similar in all quartiles. Thus the ability to clear lactate irrespective of the mechanism and its association with improved biomarkers suggests that further studies are needed to examine global tissue hypoxia as an inciting factor in the pathogenic pathways of severe sepsis and septic shock. Which of the three pathogenic pathways predominate as an association to tissue hypoxia cannot be discerned by this exploratory study. Nonetheless, our observation of a significant correlation of lactate clearance and decrease mortality is consistent with previous studies.

We have previously shown that early goal-directed therapy is significantly more effective than standard therapy in decreasing lactate (by $44 \%$ compared to $29 \%$, $\mathrm{p}<0.01$ ) during the first 6 hours, resulting in improved organ dysfunction and mortality [7]. We further showed that global tissue hypoxia and early goal-directed therapy were associated with distinct biomarker patterns that were evident as early as 3 hours after intervention [2]. The purpose of this study was to show that lactate clearance is associated with improved biomarkers and organ dysfunction scores. We a priori chose not to distinguish lactate clearance, biomarker responses, and organ dysfunction scores by resuscitation groups. While we have shown that lactate clearance is a mechanistic link in the early pathogenesis of sepsis, these findings do not support the substitution of lactate clearance as an independent alternative to an organized hemodynamic optimization strategy such as early goal-directed therapy.

\section{Conclusions}

This study showed a significant association between lactate clearance and biomarkers of pro- and anti-inflammation, coagulation, apoptosis; and further with multiorgan dysfunction and mortality in severe sepsis and septic shock. These findings support a growing body of evidence suggesting that global tissue hypoxia plays a crucial role in the complex mechanisms leading to the endothelial response in severe sepsis and septic shock rather than a terminal event. Future studies examining the pathogenic mechanisms or novel therapies for severe sepsis and septic shock should include lactate 
clearance as a measure of prognosis and therapeutic responses.

\section{Acknowledgements}

We would like to thank Quanniece Rivers, BS; Katie Floyd, MA; Shajuana Rivers; Stacie Young; Ruben Flores, PhD; Scott Rongey, PhD; Scok-Won Lee, PhD; H. Matilda Horst, MD; Kandis K. Rivers, MD; Damon Goldsmith; Peter Nwoke, MD; Joseph Garcia, MD; Bernhard Knoblich, MD; the nursing, technical, administrative and support staff in the emergency department and intensive care units. We are also grateful to the Department of Emergency Medicine nurses, residents, senior staff attending physicians, pharmacists, patient advocates, technicians, billing and administration personnel; medical and surgical ICU nurses and technicians; and the Departments of Respiratory Therapy, Pathology, Medical Records, and Admitting and Discharge at Henry Ford Hospital for their patience and cooperation in making this study possible. This study was supported by the Fund for Research of Henry Ford Hospital and the Kumasi-Rivers Foundation.

\section{Author details}

${ }^{1}$ Department of Emergency Medicine, Henry Ford Hospital, Detroit, MI, USA. ${ }^{2}$ Department of Surgery, Henry Ford Hospital, Detroit, MI, USA. ${ }^{3}$ Department of Anesthesiology, Henry Ford Hospital, Detroit, MI, USA. ${ }^{4}$ Department of Biostatistics and Epidemiology, Henry Ford Hospital, Detroit, MI, USA. ${ }^{5}$ Department of Emergency Medicine, Loma Linda University, Loma Linda, CA. ${ }^{6}$ Department of Internal Medicine, Pulmonary and Critical Care Medicine, Loma Linda University, Loma Linda, CA.

\section{Authors' contributions}

HBN, EPR were responsible for the study design and interpretation of the data. JJY, GJ performed the statistical analyses. HBN, EPR approved the final submission of the manuscript. All authors contributed to the data collection, drafting of the manuscript and provided critical revision of the manuscript for intellectual content.

\section{Competing interests}

The authors declare that they have no competing interests.

Received: 4 September 2009

Accepted: 28 January 2010 Published: 28 January 2010

\section{References}

1. Karimova A, Pinsky DJ: The endothelial response to oxygen deprivation: biology and clinical implications. Intensive Care Med 2001, 27:19-31.

2. Rivers EP, Kruse JA, Jacobsen G, Shah K, Loomba M, Otero R, Childs EW: The influence of early hemodynamic optimization on biomarker patterns of severe sepsis and septic shock. Crit Care Med 2007, 35:2016-24.

3. Marshall JC: Inflammation, coagulopathy, and the pathogenesis of multiple organ dysfunction syndrome. Crit Care Med 2001, 29:599-106.

4. Marshall JC, Vincent JL, Fink MP, Cook DJ, Rubenfeld G, Foster D, Fisher CJ $J r$, Faist $E$, Reinhart $K$ : Measures, markers, and mediators: toward a staging system for clinical sepsis. A report of the Fifth Toronto Sepsis Roundtable, Toronto, Ontario, Canada, October 25-26, 2000. Crit Care Med 2003, 31:1560-7.

5. Nadiri A, Wolinski MK, Saleh M: The inflammatory caspases: key players in the host response to pathogenic invasion and sepsis. J Immunol 2006, 177:4239-45.

6. Trzeciak S, Rivers EP: Emergency department overcrowding in the United States: an emerging threat to patient safety and public health. Emerg Med J 2003, 20:402-5.

7. Rivers E, Nguyen B, Havstad S, Ressler J, Muzzin A, Knoblich B, Peterson E, Tomlanovich M: Early goal-directed therapy in the treatment of severe sepsis and septic shock. N Engl J Med 2001, 345:1368-77.

8. Jones AE, Brown MD, Trzeciak S, Shapiro NI, Garrett JS, Heffner AC, Kline JA: The effect of a quantitative resuscitation strategy on mortality in patients with sepsis: a meta-analysis. Crit Care Med 2008, 36:2734-9.

9. Dellinger RP, Levy MM, Carlet JM, Bion J, Parker MM, Jaeschke R, Reinhart K, Angus DC, Brun-Buisson C, Beale R, Calandra T, Dhainaut JF, Gerlach $H_{\text {, }}$ Harvey M, Marini JJ, Marshall J, Ranieri M, Ramsay G, Sevransky J, Thompson BT, Townsend S, Vender JS, Zimmerman JL, Vincent JL:
Surviving Sepsis Campaign: international guidelines for management of severe sepsis and septic shock: 2008. Crit Care Med 2008, 36:296-327.

10. Nguyen $H B$, Rivers EP, Knoblich BP, Jacobsen G, Muzzin A, Ressler JA: Tomlanovich MC. Early lactate clearance is associated with improved outcome in severe sepsis and septic shock. Crit Care Med 2004, 32:1637-42.

11. American College of Chest Physicians/Society of Critical Care Medicine Consensus Conference: definitions for sepsis and organ failure and guidelines for the use of innovative therapies in sepsis. Crit Care Med 1992, 20:864-74.

12. Cohen J: The immunopathogenesis of sepsis. Nature 2002, 420:885-91.

13. Weil MH, Afifi AA: Experimental and clinical studies on lactate and pyruvate as indicators of the severity of acute circulatory failure (shock). Circulation 1970, 41:989-1001.

14. Kompanje EJ, Jansen TC, Hoven van der B, Bakker J: The first demonstration of lactic acid in human blood in shock by Johann Joseph Scherer (1814-1869) in January 1843. Intensive. Care Med 2007, 33:1967-71.

15. Vincent JL, Dufaye P, Berre J, Leeman M, Degaute JP, Kahn RJ: Serial lactate determinations during circulatory shock. Crit Care Med 1983, 11:449-51.

16. Bakker J, Gris P, Coffernils M, Kahn RJ, Vincent JL: Serial blood lactate levels can predict the development of multiple organ failure following septic shock. Am J Surg 1996, 171:221-6.

17. James JH, Luchette FA, McCarter FD, Fischer JE: Lactate is an unreliable indicator of tissue hypoxia in injury or sepsis. Lancet 1999, 354:505-8.

18. Mikkelsen ME, Miltiades AN, Gaieski DF, Goyal M, Fuchs BD, Shah CV, Bellamy SL, Christie JD: Serum lactate is associated with mortality in severe sepsis independent of organ failure and shock. Crit Care Med 2009, 37:1670-7.

19. Yang CS, Qiu HB, Huang YZ, Xie JF, Mo M, Liu SQ, Yang Y: Prospective research on the prognosis of septic shock based on the change of lactate concentration in arterial blood. Zhonghua Wai Ke Za Zhi 2009, 47:685-8.

20. Seear MD, Scarfe JC, LeBlanc JG: Predicting major adverse events after cardiac surgery in children. Pediatr Crit Care Med 2008, 9:606-11.

21. Basaran M, Sever K, Kafali E, Ugurlucan M, Sayin OA, Tansel T, Alpagut U, Dayioglu E, Onursal E: Serum lactate level has prognostic significance after pediatric cardiac surgery. J Cardiothorac Vasc Anesth 2006, 20:43-7.

22. Maillet JM, Le Besnerais $P$, Cantoni $M$, Nataf $P$, Ruffenach $A$, Lessana $A$, Brodaty D: Frequency, risk factors, and outcome of hyperlactatemia after cardiac surgery. Chest 2003, 123:1361-6.

23. Rady MY, Rivers EP, Martin GB, Smithline H, Appleton T, M NR: Continuous central venous oximetry and shock index in the emergency department: use in the evaluatio of clinical shock. American Journal of Emergency Medicine 1992, 10:538-41.

24. Kliegel A, Losert H, Sterz F, Holzer M, Zeiner A, Havel C, Laggner AN: Serial lactate determinations for prediction of outcome after cardiac arrest. Medicine (Baltimore) 2004, 83:274-9.

25. Abramson D, Scalea TM, Hitchcock R, Trooskin SZ, Henry SM, Greenspan J: Lactate clearance and survival following injury. J Trauma 1993, 35:584-8, discussion 588-9.

26. McNelis J, Marini CP, Jurkiewicz A, Szomstein S, Simms HH, Ritter G, Nathan IM: Prolonged lactate clearance is associated with increased mortality in the surgical intensive care unit. Am J Surg 2001, 182:481-5.

27. Watanabe I, Mayumi T, Arishima T, Takahashi H, Shikano T, Nakao A, Nagino M, Nimura Y, Takezawa J: Hyperlactemia can predict the prognosis of liver resection. Shock 2007, 28:35-8.

28. Antonelli M, Levy M, Andrews PJ, Chastre J, Hudson LD, Manthous C, Meduri GU, Moreno RP, Putensen C, Stewart T, Torres A: Hemodynamic monitoring in shock and implications for management. International Consensus Conference, Paris, France, 27-28 April 2006. Intensive Care Med 2007, 33:575-90.

29. Aduen J, Bernstein WK, Khastgir T, Miller J, Kerzner R, Bhatiani A, Lustgarten J, Bassin AS, Davison L, Chernow B: The use and clinical importance of a substrate-specific electrode for rapid determination of blood lactate concentrations. JAMA 1994, 272:1678-85.

30. Levy MM, Macias WL, Vincent JL, Russell JA, Silva E, Trzaskoma B, Williams MD: Early changes in organ function predict eventual survival in severe sepsis. Crit Care Med 2005, 33:2194-2201. 
31. De Backer D, Verdant C, Chierego M, Koch M, Gullo A, Vincent JL: Effects of drotrecogin alfa activated on microcirculatory alterations in patients with severe sepsis. Crit Care Med 2006, 34:1918-24.

32. Shreeniwas R, Koga S, Karakurum M, Pinsky D, Kaiser E, Brett J, Wolitzky BA, Norton C, Plocinski J, Benjamin W, et al: Hypoxia-mediated induction of endothelial cell interleukin-1 alpha. An autocrine mechanism promoting expression of leukocyte adhesion molecules on the vessel surface. $J$ Clin Invest 1992, 90:2333-9.

33. Yan SF, Tritto I, Pinsky D, Liao H, Huang J, Fuller G, Brett J, May L, Stern D: Induction of interleukin 6 (IL-6) by hypoxia in vascular cells. Central role of the binding site for nuclear factor-IL-6. J Biol Chem 1995, 270:11463-71.

34. Karakurum M, Shreeniwas R, Chen J, Pinsky D, Yan SD, Anderson M, Sunouchi K, Major J, Hamilton T, Kuwabara K, et al: Hypoxic induction of interleukin-8 gene expression in human endothelial cells. J Clin Invest 1994, 93:1564-70.

35. Leeper-Woodford SK, Fisher BJ, Sugerman HJ, Fowler AAd: Pharmacologic reduction in tumor necrosis factor activity of pulmonary alveolar macrophages. Am J Respir Cell Mol Biol 1993, 8:169-75.

36. Ghezzi P, Dinarello CA, Bianchi M, Rosandich ME, Repine JE, White CW: Hypoxia increases production of interleukin-1 and tumor necrosis factor by human mononuclear cells. Cytokine 1991, 3:189-94.

37. Toda K, Kayano K, Karimova A, Naka Y, Fujita T, Minamoto K, Wang CY, Pinsky DJ: Antisense intercellular adhesion molecule-1 (ICAM-1) oligodeoxyribonucleotide delivered during organ preservation inhibits posttransplant ICAM-1 expression and reduces primary lung isograft failure. Circ Res 2000, 86:166-74

38. Wang CY, Naka Y, Liao H, Oz MC, Springer TA, Gutierrez-Ramos JC, Pinsky DJ: Cardiac graft intercellular adhesion molecule-1 (ICAM-1) and interleukin-1 expression mediate primary isograft failure and induction of ICAM-1 in organs remote from the site of transplantation. Circ Res 1998, 82:762-72.

39. Ivey CL, Williams FM, Collins PD, Jose PJ, Williams TJ: Neutrophil chemoattractants generated in two phases during reperfusion of ischemic myocardium in the rabbit. Evidence for a role for $\mathrm{C} 5 \mathrm{a}$ and interleukin-8. J Clin Invest 1995, 95:2720-8.

40. Hack CE, De Groot ER, Felt-Bersma RJ, Nuijens JH, Strack Van Schijndel RJ, Eerenberg-Belmer AJ, Thijs LG, Aarden LA: Increased plasma levels of interleukin-6 in sepsis. Blood 1989, 74:1704-10.

41. Hack CE, Hart M, van Schijndel RJ, Eerenberg AJ, Nuijens JH, Thijs LG, Aarden LA: Interleukin-8 in sepsis: relation to shock and inflammatory mediators. Infect Immun 1992, 60:2835-42.

42. Phua J, Koay ES, Lee KH: Lactate, procalcitonin, and amino-terminal proB-type natriuretic peptide versus cytokine measurements and clinical severity scores for prognostication in septic shock. Shock 2008, 29:328-33.

43. Gibot S, Massin F, Cravoisy A, Barraud D, Nace L, Levy B, Bollaert PE: Highmobility group box 1 protein plasma concentrations during septic shock. Intensive Care Med 2007, 33:1347-53.

44. Sama AE, D'Amore J, Ward MF, Chen G, Wang H: Bench to bedside: HMGB1-a novel proinflammatory cytokine and potential therapeutic target for septic patients in the emergency department. Acad Emerg Med 2004, 11:867-73.

45. Levi M, ten Cate H, Poll van der T, van Deventer SJ: Pathogenesis of disseminated intravascular coagulation in sepsis. Jama 1993, 270:975-9.

46. Kobayashi S, Gando S, Morimoto Y, Nanzaki S, Kemmotsu O: Serial measurement of arterial lactate concentrations as a prognostic indicator in relation to the incidence of disseminated intravascular coagulation in patients with systemic inflammatory response syndrome. Surg Today 2001, 31:853-9.

47. Lorente JA, Garcia-Frade LJ, Landin L, de Pablo R, Torrado C, Renes E, Garcia-Avello A: Time course of hemostatic abnormalities in sepsis and its relation to outcome. Chest 1993, 103:1536-42.

48. Shorr AF, Thomas SJ, Alkins SA, Fitzpatrick TM, Ling GS: D-dimer correlates with proinflammatory cytokine levels and outcomes in critically ill patients. Chest 2002, 121:1262-8.

49. Quick G, Eisenberg P: Bedside measurement of D-dimer in the identification of bacteremia in the emergency department. J Emerg Med 2000, 19:217-23.

50. Bernard GR, Vincent JL, Laterre PF, LaRosa SP, Dhainaut JF, LopezRodriguez A, Steingrub JS, Garber GE, Helterbrand JD, Ely EW, Fisher CJ Jr: Efficacy and safety of recombinant human activated protein $C$ for severe sepsis. N Engl J Med 2001, 344:699-709.
51. Hotchkiss RS, Tinsley KW, Swanson PE, Karl IE: Endothelial cell apoptosis in sepsis. Crit Care Med 2002, 30:S225-8.

52. Oberholzer C, Oberholzer A, Clare-Salzler M, Moldawer LL: Apoptosis in sepsis: a new target for therapeutic exploration. Faseb J 2001, 15:879-92.

53. Chang KC, Unsinger J, Davis CG, Schwulst SJ, Muenzer JT, Strasser A, Hotchkiss RS: Multiple triggers of cell death in sepsis: death receptor and mitochondrial-mediated apoptosis. Faseb J 2007, 21:708-19.

54. Brunelle JK, Chandel NS: Oxygen deprivation induced cell death: an update. Apoptosis 2002, 7:475-82

55. Panacek EA, Marshall JC, Albertson TE, Johnson DH, Johnson S, MacArthur RD, Miller M, Barchuk WT, Fischkoff S, Kaul M, Teoh L, Van Meter L, Daum L, Lemeshow S, Hicklin G, Doig C: Efficacy and safety of the monoclonal anti-tumor necrosis factor antibody $F\left(a b^{\prime}\right) 2$ fragment afelimomab in patients with severe sepsis and elevated interleukin-6 levels. Crit Care Med 2004, 32:2173-82.

56. Opal SM, Fisher CJ Jr, Dhainaut JF, Vincent JL, Brase R, Lowry SF, Sadoff JC, Slotman GJ, Levy H, Balk RA, Shelly MP, Pribble JP, LaBrecque JF, Lookabaugh J, Donovan H, Dubin H, Baughman R, Norman J, DeMaria E, Matzel K, Abraham E, Seneff M: Confirmatory interleukin-1 receptor antagonist trial in severe sepsis: a phase III, randomized, double-blind, placebo-controlled, multicenter trial. The Interleukin-1 Receptor Antagonist Sepsis Investigator Group. Crit Care Med 1997, 25:1115-24.

57. Sevransky JE, Nour S, Susla GM, Needham DM, Hollenberg S, Pronovost P. Hemodynamic goals in randomized clinical trials in patients with sepsis: a systematic review of the literature. Crit Care 2007, 11:R67.

doi:10.1186/1476-9255-7-6

Cite this article as: Nguyen et al:: Early lactate clearance is associated with biomarkers of inflammation, coagulation, apoptosis, organ dysfunction and mortality in severe sepsis and septic shock. Journal of Inflammation 2010 7:6.

\section{Submit your next manuscript to BioMed Central and take full advantage of:}

- Convenient online submission

- Thorough peer review

- No space constraints or color figure charges

- Immediate publication on acceptance

- Inclusion in PubMed, CAS, Scopus and Google Scholar

- Research which is freely available for redistribution

Submit your manuscript at www.biomedcentral.com/submit
C Biomed Central 